\title{
THE AFRICAN HUNTING DOG: A WILD LIFE MANAGEMENT INCIDENT
}

\author{
By R. I. G. Attwell
}

\section{Northern Rhodesia Game Department}

The 1957 dry season in the Luangwa Valley was an extended one and the rains were almost a month overdue, when at the end of November a visit was paid to a salt pan in the Nsefu Game Reserve. Because the pan provided the only water, over approximately 20 square miles of arid country, there should have been as in former seasons, a constant coming and going of various species, such as impala, hartebeeste, zebra and warthog. But although there were signs of these, only the larger animals such as buffalo, elephant and rhino appeared to be visiting the pan in their usual numbers. The reason for the lack of smaller ungulates was obvious : a pack of twenty-four hunting dogs was in residence-three adult females, four adult males and seventeen young-all of which were capable of hunting.

That the dogs were in residence and not merely visiting was clear. There were small groups of vultures dotted about on the water's edge, mostly engaged in pecking at the remains of carrion. All four species found in the valley were present. Marabou storks and eagles, a Tawny and a Wahlberg's, were scavenging, while several black kites were snatching morsels from among the dogs.

The pack seemed to be in good condition. Hardly had we arrived before a kill was witnessed. Two hundred yards from the pan, a few dogs caught a baby warthog which was accompanying its parents along a path leading out of the mopane scrub. In a few seconds it was torn to pieces, the dogs immediately returning to the water's edge with their lumps of meat and settling down to feed. The parent warthogs seemed quite unconcerned. Then a second mask, carried by a dog, was identified -another young warthog had been killed in the scrub.

Although there is no cover within at least a hundred yards of this large pan and the various groups of dogs were disturbed from time to time by the vehicle approaching, yet none made an attempt to leave the immediate area. It seemed that the pan provided an ideal temporary habitat, where all the basic needs were satisfied, as well as that of comfort-for at this, the warmest period of the year, the dogs spent a considerable time lying in the mud margins. Pups were observed on several 
occasions gambolling with each other. During our first stay of two hours, nothing but occasional impalas (but never young, although calving was complete) and two hartebeeste approached ; only the impala drank, and they at places remote from the dogs.

That the dogs were really residents in the area was confirmed on our return visits the following day and the day after; for there was more evidence of the year's crop of young animals falling an easy prey. A piece of impala skin here, the skull of a young impala there, groups of vultures still sitting about on the water's edge. An adult dog loping off into the bush was at once followed by several others, and after a short interval all returned with fresh lumps of meat. Another young warthog had gone.

In assessing the consequences of this sustained predation on the year's crop of young, an important factor was consideredthe size of the reserve, a small unit of just over 80 square miles and not a complete ecological one at that. The lack of cover did not allow an unobserved appronch by prey needing water and so any young ungulates which the dogs felt inclined to take were doomed. How long the dogs had been resident could not, of course, be determined.

In the Eastern Province game reserves the predator is regarded as being as important as the prey, and therefore entitled to equal protection. But was the wild dog under these particular circumstances to be left alone? Possibly all that has been written against the species subconsciously influenced the writer's decision ; but that apart, it seemed necessary to move the pack away from the water and if possible to ensure that it would not return immediately on the departure of the humans. Leaving the vehicle and displaying oneself elicited only the characteristic rumbling growl and bark, and made the dogs move off a short distance. Control seemed essential and three animals had to be shot before the rest were sufficiently disturbed to go loping off into the bush. It appeared that a wounded one, bleeding and struggling on the ground, convinced the rest of the threatening danger; for a number approached closely, obviously curious. Other observers have recorded that cannibalism in such circumstances is not unusual but these made no attempt to feed. Perhaps they were too well-fed to eat one of their own kind, and certainly those destroyed were in good condition. Immediately after investigation of the wounded one, the pack formed up and departed. Within a minute or two, fifty impala with young were drinking a hundred yards from the place where the dogs had disappeared into the bush. 
Why was the decision made to move the dogs out of the area? While it was appreciated that normal predation has little effect on the succeeding year's crop of game (Gabrielson, Oryx, Volume IV, No. 2), nevertheless it was considered that the cumulative effect of the factors recorded above presented a sufficiently abnormal state of affairs to warrant interference in Nature's business. Had the rains been normal, the concentrations of ungulates in the vicinity of the pan would long since have dispersed, and the dogs would have been forced to hunt for their prey, rather than have it come willy-nilly to them, unable to approach the water without displaying itself from afar to the keen eyes of the predator. Although in fact the rains came a few days later, the presence of the dogs for an unknown period might already have been a serious limiting factor. 


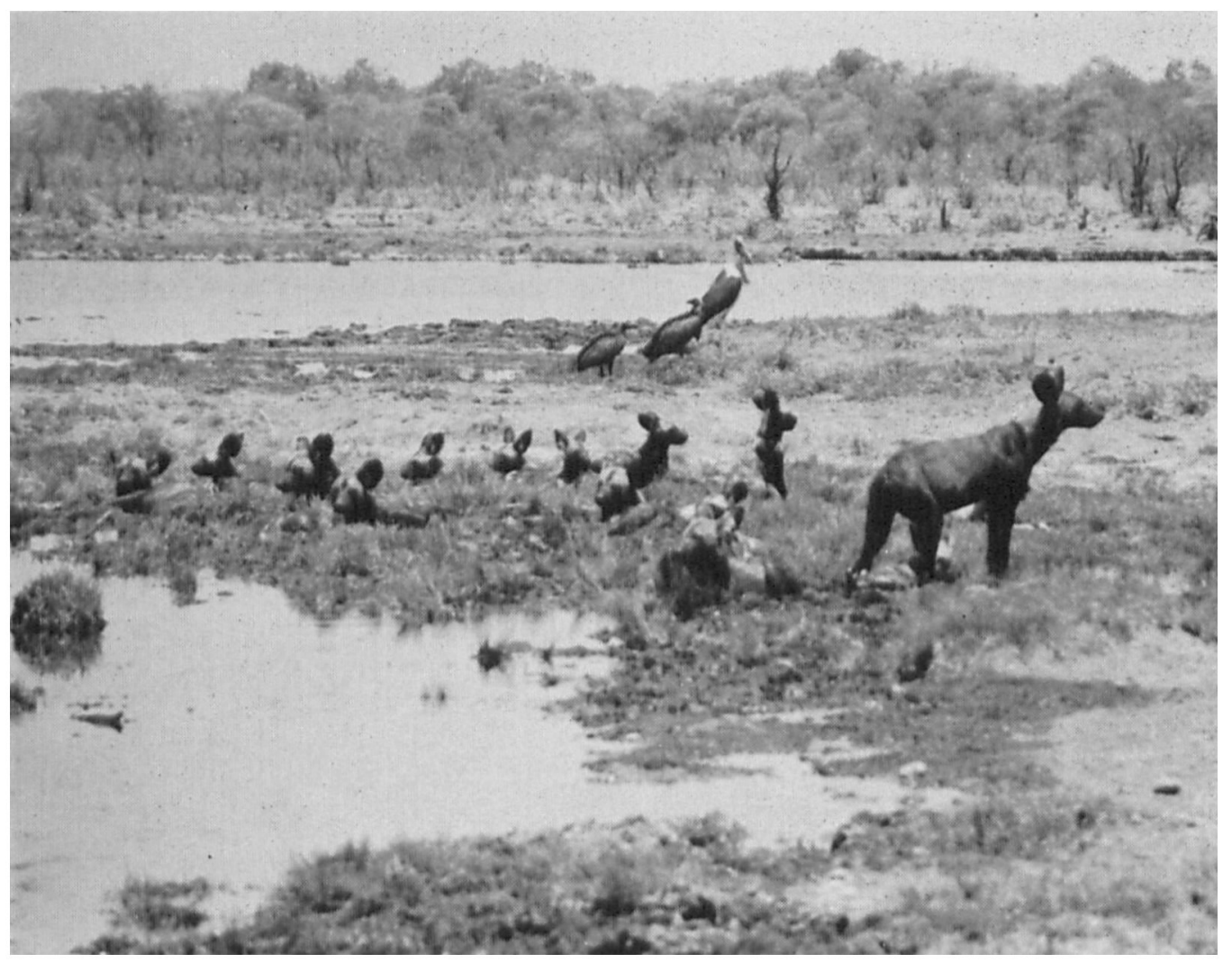

Whoto: R. I. G. Attitll.

AFRICAN HIT'NING IOOG WITH MARABOE STORK ANI) VILTIRLS.

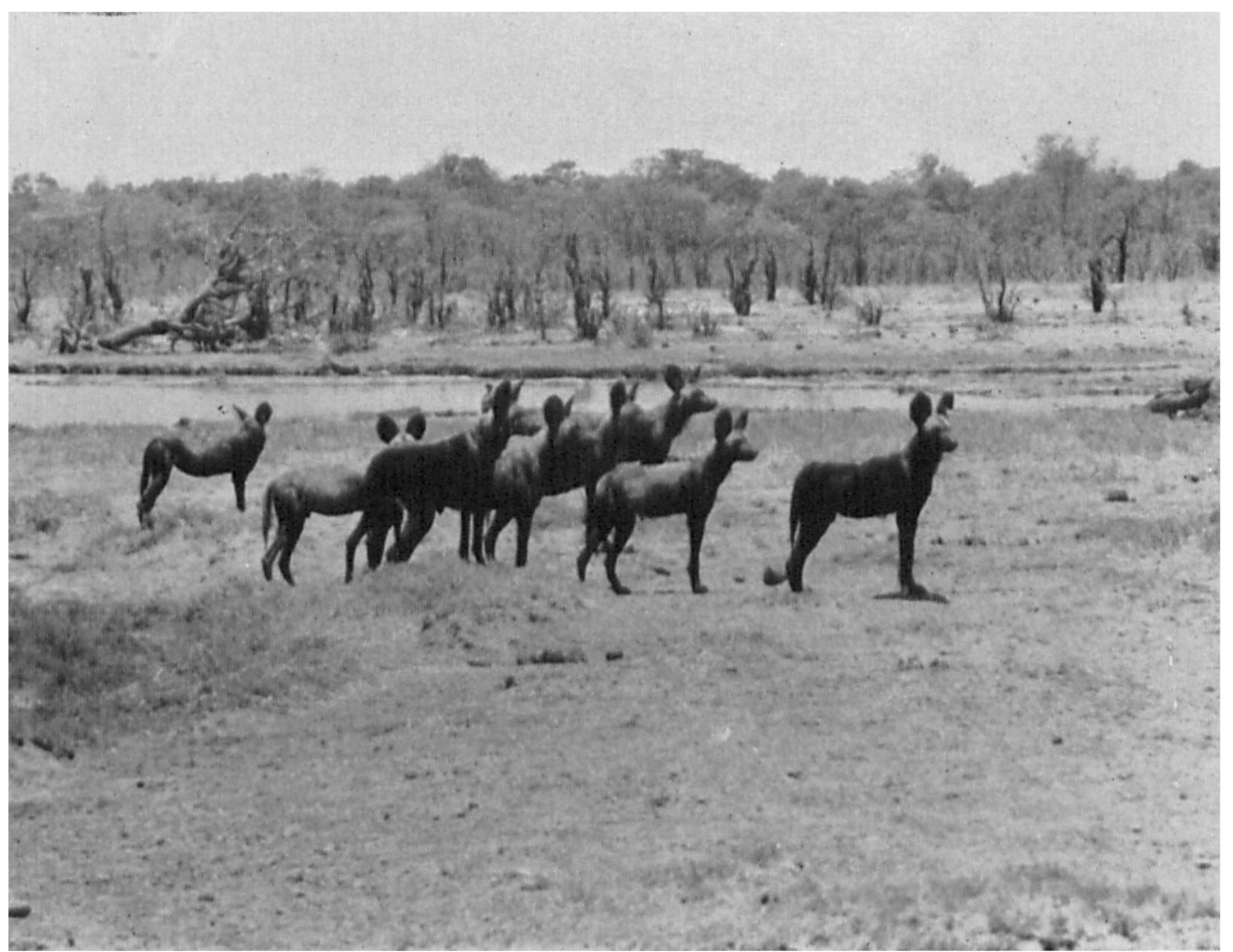

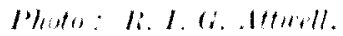

AFRICAN IIINTING IOOG. 


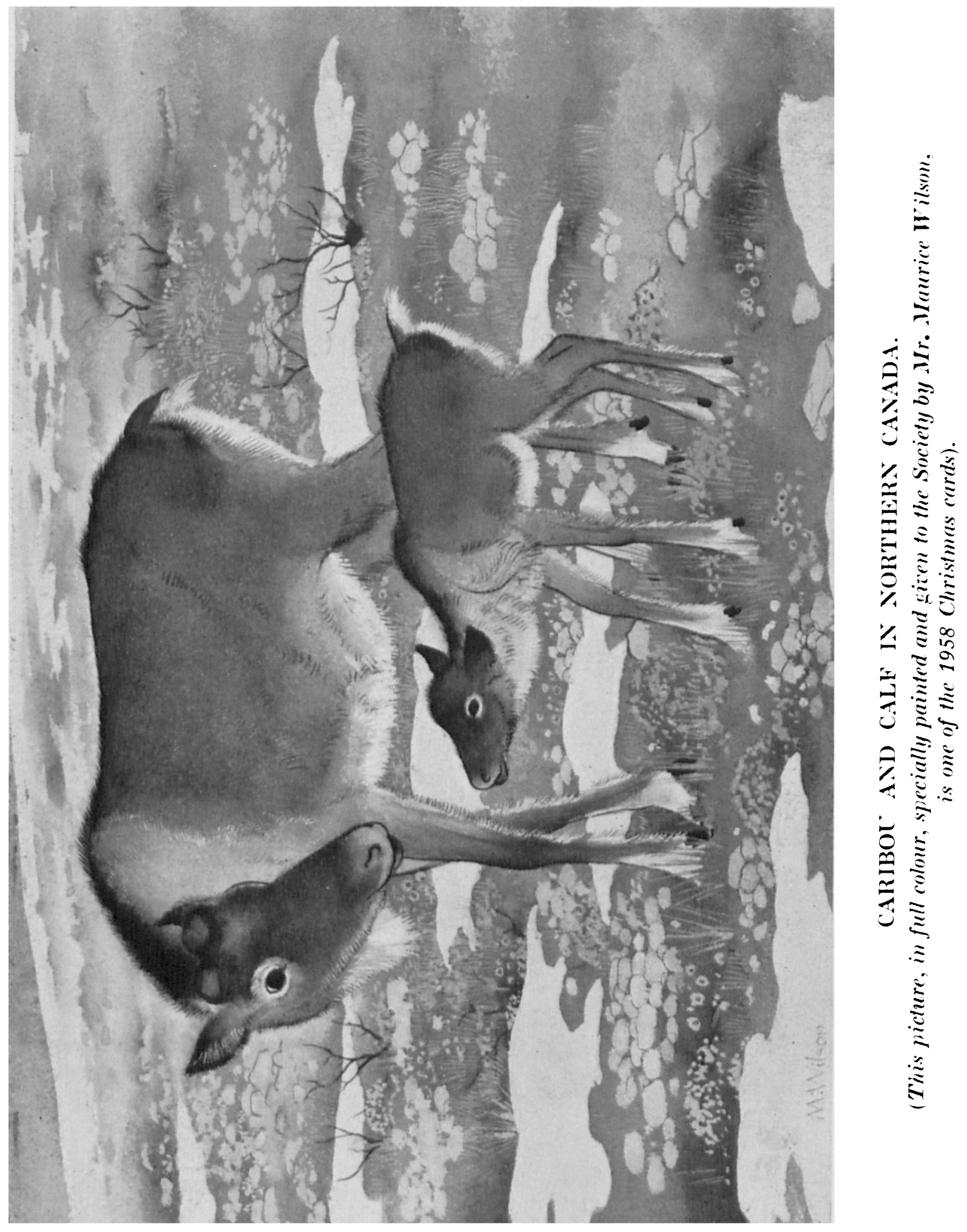

